\title{
Influence of Rice Straw, Bagasse, and their Combination on the Properties of Binderless Particleboard ${ }^{1}$
}

\author{
Mohd Ariff JAMALUDIN ${ }^{2}$ - Shahril Anuar BAHARI(D) ${ }^{2, \dagger}$ • \\ Mohd Nazarudin ZAKARIA ${ }^{2}$ - Nurfarah Syafikah SAIPOLBAHRI ${ }^{2}$
}

\begin{abstract}
In this study, rice straw and bagasse are used as raw materials to produce binderless particleboard (BPB). This study aims to evaluate the mechanical and physical properties of BPB. We identify the raw material that would be better for the production of BPB from the viewpoint of their basic properties. The BPBs are made from rice straw, bagasse, and combinations of both in ratios of 50:50 and 40:60, respectively. The modulus of elasticity (MOE), modulus of rupture (MOR), internal bonding (IB) strength, water absorption, and thickness swelling properties of the different BPBs are determined and compared. Results showed that all the properties are significantly influenced by the type of particles or particle combinations in the BPB. BPBs made from bagasse alone have the highest MOR, MOE, and IB mean values, whereas BPBs made from rice straw alone exhibit the lowest MOR, MOE, and IB values. Meanwhile, BPBs made from a combination of rice straw and bagasse at 40:60 ratio by weight have the second highest values for properties such as MOR, MOE, and IB, followed by BPBs made from a combination of rice straw and bagasse at 50:50 ratio by weight.
\end{abstract}

Keywords: rice straw, bagasse, particleboard, binderless, mechanical properties, physical properties

\section{INTRODUCTION}

Particleboard (PB) is widely used in many applications such as building, construction, and furniture components, as well as packaging cases. It is a typicallywood-based composite consisting of varying shapes and sizes of particle material bonded together with adhesive,and consolidated under heat and pressure (Gamage et al., 2009). The most common synthetic adhesives used to bind $\mathrm{PB}$ ofthe primarily thermosetting resin are urea formaldehyde (UF) and phenol formaldehyde (PF). Although UF and PF are relatively low cost and cure rapidly, it is carcinogenic to people and environment. According to Commission Regulation EU 2014, the formaldehyde released from UF resin has been classified as hazardous and carcinogenic to humans (Laskowska and Mamiński, 2018).

$\mathrm{PB}$ can also be manufactured by pressing particles of lignocellulosic materials under a certain heat without the addition of synthetic resin and adhesive (Luo and Yang, 2012), to produce a different type of product, called binderless particleboard (BPB). The adhesives used to bond the particles are synthetic or natural adhesives derived from the wood itself. This makes

\footnotetext{
${ }^{1}$ Date Received February 12, 2019, Date Accepted October 24, 2019

${ }^{2}$ Faculty of Applied Sciences, Universiti Teknologi MARA, 40450 Shah Alam, Selangor, Malaysia

$\dagger$ Corresponding author: Shahril Anuar BAHARI (e-mail: shahril721@uitm.edu.my, ORCID: 0000-0001-9874-4822)
} 
it safer and eco-friendly to humans. As the price of wood increased year by year, more interest grows for alternative source of raw materials and technique in producing BPB. Historically, the first attempt of binderless board fabrication was conducted by Runkel and Jostin 1948, when they fabricated a highly densified molded product from fine wood particles without the addition of resin (Mobarak et al., 1982). Since then, the issues of the overuse of synthetic-plastic materials, rising prices of petroleum, shortage of wood supplies, surplus of agricultural residues, and great growth of plantation tree species have forced the researchers to study the bright potential of binderless board from bagasse, kenaf, rice husk, and maiden silvergrass (Mobarak et al., 1982; Vela'squez et al., 2002; Xu et al., 2004; Widyorini et al., 2005a and 2005b; Panyakaew and Fotios, 2011; Nonaka et al., 2013). The decreasing supply of wood raw materials and the need for formaldehyde-free PB led to studies of PB manufactured with raw materials other than wood (e.g. agricultural waste materials) and without synthetic adhesives (Widyorini et al., 2005a; Okuda, 2006), or called as BPB in this study.

A great example is agriculture sector in Malaysia, which contributes to the abundance of bagasse residues from sugar cane industry and rice straw/husk disposal from paddy field, second and third largest respectively after oil palm wastes biomass (Shafie et al., 2012). These residue materials can be converted into a new product through the combination with non-bio material such as polymer wastes or recycled polymers, or, without any combination with synthetic adhesives (called as binderless). Iswanto et al. (2018) stated that the potential utilization of plant and agricultural wastes as new and inexpensive materials for the production of composite products. The possible use of bagasse and rice straw particles as raw materials and their combination in the production of BPB may help to reduce the burden of agricultural wastes and manufacturing cost of the wood-based composites producer. Based on the literature, only Panyakaew and Fotios (2011) have focused on the mixture of agricultural waste materials (coconut husk mixed with bagasse) in the production of binderless board products. Bagasse, a waste product of sugarcane processing, is now considered to be one of the most promising nonwood lignicellulosic raw materials (Widyorini et al., 2005b), especially in the production of BPB.

In term of density, BPB of a medium density has been produced in this current study, as an advancement of the very low density binderless particleboard studied by Xu et al. (2004). Regardless of composite board types, the density increases have improved the mechanical properties of the board (Hwang and Oh, 2017), a rational of producing a slightly higher board density in this current study compared to the previous ones. As bagasse and rice straw possess relatively higher density than the other agricultural waste materials (Mansara and Ghaly, 1996; Shu et al., 2006), it is difficult to make low density particleboard using these high density materials due to the high value of compaction ratio (Xu et al., 2004).

In this current study, the BPB at $800 \mathrm{~kg} / \mathrm{m}^{3}$ density using rice straw and bagasse was produced. The mechanical properties, such as static bending and internal bonding, as well as physical properties, such as water absorption and thickness swelling, were tested, and the values were compared between different mixtures of raw materials.

\section{MATERIALS and METHODS}

\subsection{Preparation of rice straw and bagasse particles}

Dry rice straws were first cut into $1-3 \mathrm{~cm}$ length and rendered using a crusher machine. The rendered straws were soaked in water at $25^{\circ} \mathrm{C}$ for 7 days to 
soften the straw fibers and then air-dried. Next, the rice straws were crushed to reduce the straws into smaller particles. The small particles were screened to classify the particles into 20 mesh size. The fresh bagasse was collected from local market in Shah Alam, Malaysia. The raw bagasse was used in the processing, without removing its pith and residual sugar. It was also reported that the raw bagasse material can be used as it is, under the hot pressing system at an elevated temperature of $180^{\circ} \mathrm{C}$ and higher (Shen, cited in Widyorini et al. (2005b)). The bagasse was cut into $1-3 \mathrm{~cm}$ length. Then, the bagasse was air-dried for two days to reduce the moisture content. Next, the bagasse was crushed into smaller particles. The particles were then screened to classify into 20 mesh size.

\subsection{Fabrication of rice straw and bagasse BPB}

After the screening process, the particles were dried in an oven at $72^{\circ} \mathrm{C}$ for 72 hours. The particles were dried to moisture content of 6 to $8 \%$. This study produced four (4) types of medium density BPB of a targeted density of $800 \mathrm{~kg} / \mathrm{m}^{3}$. The density selection was in line with suggestion from Maulana et al. (2017) and Seo et al. (2018), which stressed out the production of medium or high density composites using high dense raw material. The first type of BPB was made from rice straw, the second type of $\mathrm{BPB}$ was from bagasse, the third type of BPB was from rice straw-bagasse combination of 50:50 ratio by weight, respectively, and the fourth type of BPB was also from rice straw-bagasse combination, but the ratio was 40:60 ratio by weight, respectively. The particles were manually laid intoa mold to form a mat. The mold size for the particleboard was $320 \times 320 \times 12 \mathrm{~mm}^{2}$. Before forming the mat, the mold releasing agent wassprayed on the inside surface of the mold to avoid the particles from sticking onto the mold surface.
After 10 minutescold pressing, the particle mat was removed from the steel mold. Pre-pressing was done to reduce the mat thickness and make it easier to handle. The mat was transferred onto the hot press and pressed at $180^{\circ} \mathrm{C}$ for 10 minutes. Then the board was removed and conditioned. The boards were placed in the conditioning room with temperature of $20^{\circ} \mathrm{C}$ and $65 \%$ relative humidity until theyreached equilibrium moisture content (EMC). Subsequently the boards were edged and trimmed. Lastly, the board was cut into test samples of specified dimensions.

\subsection{Test methods and statistical analysis}

The mechanical tests consisted of static bending and internal bonding (IB) tests. The tests were performed using a universal testing machine according to Mobarak et al. (1982). The test samples for static bending were $200 \mathrm{~mm} \times 50 \mathrm{~mm} \times 12 \mathrm{~mm}$ in dimension. The load was applied at a uniform rate of $5.0 \mathrm{~mm} / \mathrm{sec}$. The length, width and thickness of the samples were $50 \mathrm{~mm}$ $\times 50 \mathrm{~mm} \times 12 \mathrm{~mm}$, with crosshead speed of $0.5 \mathrm{~mm} / \mathrm{sec}$. All dimensions were measured with an accuracy of $\pm 0.02 \mathrm{~mm}$. Six (6) samples were tested until failure. Modulus of elasticity (MOE) and modulus of rupture (MOR) of the samples were calculated and recordedin static bending test. IB test was setup, in which each test piece was glued to loading blocks using hot melt glue. Excess glue was pressed out from the glue line and was removed. The IB test was carried out after 24 hours. During this time, the glued assembly was stored under controlled condition, at $65 \pm 5 \%$ relative humidity and $20 \pm 2^{\circ} \mathrm{C}$ temperature. The pieces were tested for not more than one (1) hour after removal from the conditioning environment. The testing was placed in the grips and force was applied until rupture occurred. The rate of loading waskept constant at cross head movement throughout the test. Six (6) samples were tested until failure at the middle section of the 
Influence of Rice Straw, Bagasse, and their Combination on the Properties of Binderless Particleboard

samples. The IB (tensile force perpendicular to the plane) values were calculated and recorded.

The physical tests consisted of water absorption (WA) and thickness swelling (TS) tests. First, the initial weight and thickness before immersion of the test samples for each type of BPB were recorded. Next, the samples were soaked into a $1000 \mathrm{ml}$ of distilled water at $25^{\circ} \mathrm{C}$ in a beaker for 24 hours. After soaking, the samples were cooled and the final weight and thickness were immediately recorded. Six (6) samples were measured in term of physical properties.

Analysis of variance (ANOVA) was conducted (p $\leq 0.05$ ) to evaluate the effect of the different particle types on the mechanical and physical properties of the BPB. Duncan's multiple range test (DMRT) was used to test if the influences were significantly different from each other.

\section{RESULTS and DISCUSSION}

\subsection{Mechanical properties of BPB}

The results of the mechanical properties of BPB are as shown in Table 1. The mechanical properties were significantly influenced by the type of particles or particles combination in the BPB, as shown in ANOVA in Table 2. According to Table 1, BPB made from bagasse had the highest MOR at $20 \mathrm{MPa}$, highest IB at $0.6 \mathrm{MPa}$, and highest MOE at $1907 \mathrm{MPa}$. The bagasse BPB had the highest value of MOR and IB due to their lignin and cellulose contents that arehigher than rice straw. Balaji et al. (2015) reported that the main composition of bagasse consisted of approximately 50\% cellulose and 25\% each of hemicellulose and lignin. Chemically, bagasse contains about 50\% $a$-cellulose, 30\% pentosans, and 2.4\% ash (Balaji et al., 2015). According to Van Hoest (2006), rice husk is known to have low lignin $\left(160 \mathrm{~g} \mathrm{~kg}^{-1}\right)$, but high silica $\left(\mathrm{SiO}_{2}\right.$ $=230 \mathrm{~g} \mathrm{~kg}^{-1}$ ) contents which influence the composite material the ceramic like properties. It was also reported by Kargbo et al. (2010) that the rice straw contains up to $17 \%$ ash, thus influences the low properties of composite products. Because of its low ash content, bagasse offers numerous advantages in comparison to other crop residues. Furthermore, Balaji et al. (2015) also reported that bagasse self-bonding area was higher than rice straw. The authors stated that bagasse had its own caramelization to make better self-bonding particles compared to rice straw used in this current study. The lowest MOR, MOE, and IB mean values in this current study were exhibited by rice straw particleboards at $13 \mathrm{MPa}, 1028 \mathrm{MPa}$, and $0.3 \mathrm{MPa}$, respectively. This was probably due to the rice straw that can easily be ruptured as it contains lower lignin but higher silica than bagasse (Ghaffar and Fan, 2014). For these reasons the bonding between rice straw particles was weaker compared to the bonding between bagasse particles. Meanwhile, BPB made from the combination of rice straw and bagasse at 40:60 ratio by weight, respectively, gave the second highest value for both MOR and IB at $18 \mathrm{MPa}$ and $0.5 \mathrm{MPa}$, respectively. The MOE was also second highest at 1210 MPa. This was due to the combined effect on bonding between the rice straw and bagasse particles. The bonding between the rice straw particles was weak because of its brittle characteristic. In addition, the low lignin and high silica content also led to poor bonding between rice straw and bagasse particles. Therefore, overall strength of the board was slightly affected. The strength of the board decreases when the percentage of bagasse, in the rice straw-bagasse particleboard, was reduced from $60 \mathrm{wt} \%$ to $50 \mathrm{wt} \%$.

Reported by Matsumoto et al. (2001), binderless board is composed of chemical content activation in the cellulosic materials, called self-bonding. This was attributed by hydrolysis of hemicellulose and softened lignin (Matsumoto et al., 2001), indicating intensive changes in the chemical composition of the lignocellulo- 
sic materials (Widyorini et al., 2005b). Widyorini et al. (2005b) studied the manufacture and properties of binderless particleboard from single bagasse raw material. The effects of bagasse types and the manufacturing processes on physical and mechanical properties of binderless particleboards were investigated. The results showed that the bagasse pith particles provided better board properties than bagasse rind particles. However, a better result was recorded in this current study. A random mixture of both bagasse pith and rind give an advantage for the industry to utilize this material, because of processing time saving and easy in processing, but yet a similar result with the bagasse binderless board product using separated materials (as in Widyorini et al., 2005b) was recorded in this current study.

A thermo-mechanical process that hydrolyzed and plasticized the hemicelluloses and lignin (Velasquez et al., 2002) is believed to be occurred in this current study. The binding elements generated from hemicelluloses during hot pressing contributed to the self-bonding element (Mobarak et al., 1982). It is believed that hot pressing parameters $\left(180^{\circ} \mathrm{C}\right)$ used in this current study have direct influence on the behaviour of self-bonding and the properties of BPB. Although the density of BPB is considered high, the lignin under this hot press condition $\left(180^{\circ} \mathrm{C}\right)$ creates the observable glass-transition temperature (thermal softening of lignin) that promotes the self-mechanism of all types of binderless board (Wang et al., 2017).
Based on the Korea Standard KS F 3104: 2002: Particleboards, Korean Standard Association, Seoul, 2006 (cited in Seo et al., 2018), the mean MOR values of particleboard must be at least $13 \mathrm{~N} / \mathrm{mm}^{2}$, while IB must be at least $0.15 \mathrm{~N} / \mathrm{mm}^{2}$. According to this current study, the MOR and IB values of BPB have conformed to this Korean standard (except BPB made from single rice straw).

Table 1. Mechanical properties of BPB

\begin{tabular}{lccc}
\hline Types of BPB & $\begin{array}{c}\text { MOE } \\
(\mathrm{MPa})\end{array}$ & $\begin{array}{c}\text { MOR } \\
(\mathrm{MPa})\end{array}$ & $\begin{array}{c}\text { IB } \\
(\mathrm{MPa})\end{array}$ \\
\hline \hline Rice Straw & 1,028 & 13 & 0.3 \\
& $(58)$ & $(2)$ & $(0.1)$ \\
Bagasse & 1,907 & 20 & 0.6 \\
& $(129)$ & $(1.6)$ & $(0.2)$ \\
Rice Straw: & 1,109 & 16 & 0.4 \\
Bagasse (50:50) & $(111)$ & $(2.6)$ & $(0.1)$ \\
Rice Straw: & 1,210 & 18 & 0.5 \\
Bagasse $(40: 60)$ & $(28)$ & $(2.3)$ & $(0.2)$ \\
\hline
\end{tabular}

Note: $\mathrm{MOE}=$ modulus of elasticity; $\mathrm{MOR}=$ modulus of rupture; IB = internal bonding; The numbers in parenthesis are the standard deviation

Table 2. ANOVA of mechanical properties of BPB made from different particle types

\begin{tabular}{lccc}
\hline Properties & Sum of Square & F-Value & Sig. \\
\hline \hline MOE & 85313.5088 & 15.48 & $0.0001^{*}$ \\
MOR & 1.10463737 & 10.8 & $0.0004^{*}$ \\
IB & 0.00035407 & 4.17 & $0.0233^{*}$ \\
\hline
\end{tabular}

Note: $*$ Significantly different at $\mathrm{p} \leq 0.05$ according to DMRT

Table 3. Mechanical properties of resin-bonded PB from other studies and sources

\begin{tabular}{|c|c|c|c|}
\hline Particleboard Products & MOE (MPa) & MOR (MPa) & IB (MPa) \\
\hline UF Particleboard from Rubberwood ${ }^{1}$ & 2447 & 23.4 & 1.3 \\
\hline UF Particleboard from Mahang ${ }^{1}$ & 1796 & 19.37 & 0.83 \\
\hline UF Particleboard from wood waste ${ }^{2}$ & 2750 & 27 & 1.5 \\
\hline UF Particleboard from palm tree-based materials ${ }^{3}$ & 988.14 & 10.76 & 0.98 \\
\hline Commercialized MIECO Particleboard UF Grade ${ }^{4}$ & - & 10.5 & 0.28 \\
\hline Commercialized MIECO Particleboard MUF Grade ${ }^{4}$ & 1950 & 14 & 0.45 \\
\hline
\end{tabular}

Note: 1 = Loh et al. (2010); 2 = Astari et al. (2018); 3 = Ferrández-García et al. (2018); 4 = http://www.mieco.com.my 
Influence of Rice Straw, Bagasse, and their Combination on the Properties of Binderless Particleboard

In comparison to the resin-bonded PB from other studies and sources, it is recorded that the mechanical properties of BPB are compatible with those products (includes commercialized PB), especially for BPB made from bagasse alone. Therefore, an advantage of BPB has been discovered, since the product has no synthetic resins at all.

\subsection{Physical properties of BPB}

The results of the physical properties of BPB are as shown in Table 4. The physical properties were significantly influenced by the type of particles or particles combination in the BPB, as shown in ANOVA in Table 5. According to Table 4, The BPB in this study showed poor water absorption (WA) and thickness swelling (TS) mean values. The BPB made from rice straw gave the lowest WA and TS values at $83.0 \%$ and $25.0 \%$, respectively. Whereas, BPB made from bagasse gave the highest WS and TS values at $141.7 \%$ and $93.4 \%$, respectively. This was due to the loss of compatibility between particles and matrices as a result of weakening of the interface adhesion, as the water molecules expand the board. Bagasse have a residual sugar that was left after squeezing or crushing of sugarcane to extract the sugarcane juice that effect WA and TS. However, during hot pressing the sugar is caramelized, forming better self-bonding particles compared to rice straw. The absorbed moisture weakens any bonding that was contributed by the caramelization of the residual sugar in the bagasse making the board weaker. As the bond weakens, more water was absorbed. The diffusing water molecules may also strain or rupture the intermolecular bonds in the fiber, matrix and at the interface between fiber and matrix.

Even though the highest percentage of WA and TS were exhibited by bagasse, but, when combinedwith rice straw, the particleboard produced gave better resistant towards WA and TS than when bagasse was used alone. This was due to the characteristic of rice husk which has lower WA and TS behaviour compared to bagasse. The trend was that the WA and TS were

Table 4. Physical properties of BPB

\begin{tabular}{lcc}
\hline \multicolumn{1}{c}{ Types of BPB } & WA (\%) & TS (\%) \\
\hline \hline Rice Straw & $83(1.3)$ & $35(2.7)$ \\
Bagasse & $142(6.6)$ & $93(5.0)$ \\
Rice Straw:Bagasse (50:50) & $93(7)$ & $47(6)$ \\
Rice Straw:Bagasse (40:60) & $110(10.3)$ & $61(6.5)$ \\
\hline
\end{tabular}

Note: WA=Water Absorption; TS=Thickness Swelling; The numbers in parenthesis are the standard deviation

Table 5. ANOVA of physical properties of BPB made from different particle types

\begin{tabular}{cccc}
\hline Properties & Sum of Square & F-Value & Sig. \\
\hline \hline WA & 36723.03309 & 33.76 & $0.0001^{*}$ \\
TS & 17984.29082 & 37.81 & $0.0001^{*}$ \\
\hline
\end{tabular}

*Significantly different at $\mathrm{p} \leq 0.05$ according to DMRT

Table 6. Physical properties of resin-bonded PB from other studies and sources

\begin{tabular}{lcc}
\hline \multicolumn{1}{c}{ Particleboard Products } & WA (\%) & TS (\%) \\
\hline \hline UF Particleboard from Rubberwood ${ }^{1}$ & 69.39 & 13.19 \\
UF Particleboard from Mahang ${ }^{1}$ & 65.19 & 13.23 \\
UF Particleboard from wood waste ${ }^{2}$ & - & 9.5 \\
UF Particleboard from palm tree-based materials ${ }^{3}$ & 74.91 & 33.03 \\
Commercialized MIECO Particleboard UF Grade $^{4}$ & - & - \\
Commercialized MIECO Particleboard MUF Grade $^{4}$ & - & 14 \\
\hline
\end{tabular}

Note: 1 = Loh et al. (2010); 2 = Astari et al. (2018); 3 = Ferrández-García et al. (2018); 4 = http://www.mieco.com.my 
lower for the rice straw-mixed particleboard, thus indicates better performance in term of water resistance. In contrast, although the mechanical properties of bagasse BPB were higher, however, its WA and TS resistance were lower.

In comparison to the resin-bonded PB from other studies and sources, it is recorded that the physical properties of BPB are critically inferior compared to those products (includes commercialized PB), especially for BPB made from bagasse alone. It is observed that the drawback of WA and TS of BPB, especially BPB made from bagasse alone, was up to $118 \%$ higher than the resin-bonded PB. Therefore, it is discussed that the BPB made from bagasse possesses compatible quality in term of mechanical properties, however, in contrast, a very low resistant towards water.

Based on the WA and TS results, there are some critical suggestions in order to overcome this serious issue. It is suggested that the density of the board may be further increased inthe future study. This is based on Zhang et al. (2018) statement, which discussed the possibility of increasing the density of a composite board into its maximum, in order to reduce water absorption and thickness swelling rate. The dimensional stability (in this current study called WA and TS resistance) will be improvedwith the increasing density of composite board, due to the reduction of internal void volume (Zhang et al., 2018).

On the other hand, bio-based resins are still in a good agreement with the purpose of this current study, which focuses on the natural-bonded composites. As an example, maltodextrin binder (a starch-based polysaccharide produced by hydrolysis of starch down to glucose polymers with an average chain length of 5 to 10 glucose units) is possibly to be blended with other natural particles (Santoso et al., 2017). It is expected that the small amount of maltodextrinmay provide better adhesion of natural particles for physical resistance. Another example isthe use of citric acid bind- er as a cross-linking agent (Santoso et al., 2017), that may possibly react as an excellent bonding agent for natural particles in the fabrication of binderless particleboard. By adding the citric acid in the composites, or the combination of citric acid and maltodextrin, the carbonyl groups from citric acid will combine with hydroxyl group from natural paarticles, thus reduce the hygroscopicity (Santoso et al., 2017).This possibly help the BPB to resist to water absorption and thickness swelling, and reduce the percentage of WA and TS of the board. Santoso et al. (2017) also reported that the water absorption and thickness swelling of nipa frond board in their study has been reduced by almost $100 \%$ when the maltodextrin and citric acid were combined together in the composition. Apart from bio-based resin, the board can also be mixed up with a very small amount of synthetic resins (e.g. amino resins), in order to reduce the rate of water absorption and thickness swelling of the board. This was proved by Iswanto et al. (2017) in their study on the physical and mechanical properties of wood particleboard, in which the combination of a small amount of urea formaldehyde and urea melamine formaldehyde has improved the resistance of the board towards moisture.

It is also suggested that the particles are treated by acetylation and paraffin in order to solve the issue of dimensional stability (Iswanto et al., 2018). Alternatively, the particles can also be treated using superheated steam (SHS), as suggested by Park et al. (2016b), in their study on the evaluation of physical and mechanical properties of solid wood. The physical resistance and compression properties of SHS-treated solid wood were increased, therefore, it is expected that basic properties of bagasse and rice straw particles in this study may be increased in term of physical resistance for a better water resilience performance of BPB. The other possible method is surface and edge lamination with various laminating materials such as wood veneers and polymer films. This lamination technique 
will not only protect the BPB from absorbing more water and moisture, but also, according to Park et al. (2016a), to reduce any types of emission from the board.

\section{CONCLUSION}

This study evaluated the mechanical and physical properties of rice straw, bagasse and rice straw/ bagasse-based BPB. All types of BPB were found to be significantly different from each other. The type and combination of particles significantly influenced the mechanical and physical properties. BPB made from rice straw showed worst mechanical properties, but the best percentage of water absorption. Combining rice straw with bagasse improved the mechanical and physical properties of BPB. The BPB made from bagasse alone exhibited best mechanical properties, but worst percentage water absorption. Hence, bagasse is a better raw material for a stronger BPB than rice straw. The second highest mechanical properties were BPB made from combination of rice straw and bagasse particles at 40:60 ratio by weight, respectively. The third highest mechanical properties were displayed by BPB from 50:50 ratio by weight of rice straw and bagasse combination, respectively. It seemed that the rice straw was the weakening factor of the bond strength of the BPB. It was also found that the rice straw had a potential to be brittle when stored more than 3 months. This affected slightly their performance of the mechanical and physical properties. Rice straw should be used fresh.

\section{REFERENCES}

Astari, L., Prasetiyo, K.W., Suryanegara, L. 2018. Properties of particleboard made from wood waste with various size. IOP Conference Series: Earth and Environmental Science 166: doi: 10.1088/17551315/166/1/012004
Balaji, A., Karthikeyan, B., Sundar Raj, C. 2015. Bagasse fiber, the future biocomposite material: A review. International Journal of Chemtech Research 7(1): 223-233.

Ferrández-García, C.F., Ferrández-García, A., FerrándezVillena, M., Hidalgo-Cordero, J.F., García-Ortuño, T., Ferrández-García, M.T. 2018. Physical and Mechanical Properties of Particleboard Made from Palm Tree Prunings. Forests 9(12): 755. doi: $10.3390 / f 9120755$

Gamage, N., Setunge, S., Jollands, M., Hague, J. 2009. Properties of hardwood saw mill residue-based particleboards as affected by processing parameters. Industrial Crops and Products 29(1): 248-254.

Ghaffar, S.H., Fan, M. 2014. International Journal of Adhesion \& Adhesives Lignin in straw and its applications as an adhesive. International Journal of Adhesion and Adhesives, 48: 92-101.

doi: 10.1016/j.ijadhadh.2013.09.001

Hwang, J.W., Oh, S.W. 2017. Physical and mechanical properties of board from carbonized rice husk. Journal of the Korean Wood Science and Technology 45(1): 62-71.

Kargbo, F.R., Xing, J., Zhang, Y. 2010. Property Analysis and pretreatment of rice straw for energy use in grain drying: a review. Agriculture and Biology Journal of North America 1(3): 195-200.

Iswanto, A.H., Simarmata, J., Fatriasari, W., Azhar, I., Sucipto, T., Hartono, R. 2017. Physical and mechanical properties of three-layer particleboards bonded with uf and umf adhesives. Journal of the Korean Wood Science and Technology 45(6): 787796.

Iswanto, A.H., Febrianto, F., Hadi, Y.S., Ruhendi, S., Hermawan, D., Fatriasari, W. 2018.Effect of particle pre-treatment on properties of jatropha fruit hulls particleboard. Journal of the Korean Wood Science and Technology 46(2): 155-165.

Laskowska, A., Mamiński, M. 2018. Properties of 
particleboard produced from post-industrial UFand PF bonded plywood. European Journal of Wood and Wood Products 76: 427-435.

Luo, P., Yang, C. 2012. Production of binderless particleboard using rice straw pretreated with liquid hot water. Applied Mechanics and Materials 200: 331334.

Loh, Y.W., H’ng, P.S., Lee, S.H., Lum, W.C., Tan, C.K. 2010. Properties of particleboard produced from admixture of rubberwood and mahang species. Asian Journal of Applied Sciences 3(5): 310-316.

Mansaray, K.G., Ghaly, A.E. 1996. Physical and thermochemical properties of rice husk. Journal of Energy Sources 19(9): 989-1004.

Matsumoto, S., Yamazaki, T., Takemura, I. 2001. Development of using technique for unused ligneous material: forming woodenboard without adhesive (in japanese). Saitama Prefecture Industrial Technology Center Report 3: 1-4.

Maulana, S., Busyra, I., Fatrawana, A., Hidayat, W., Sari, R. K., Sumardi, I., Wistara, I.N.J., Lee, S.H., Kim, N.H., Febrianto, F. 2017. Effects of steam treatment on physical and mechanical properties of bamboo oriented strand board. Journal of the Korean Wood Science and Technology 45(6): 872882.

Mobarak, F., Fahmy, Y., Augustin, H. 1982. Binderless lignocellulose composite from bagasse and mechanism of self-bonding. Holzforschung 36(3): 131135.

Nonaka, S., Umemura, K., Kawai, S. 2013. Characterization of bagasse binderless particleboard manufactured in high-temperature range. Journal of Wood Science 59: 50-56.

Okuda, N., Hori, K., Sato, M. 2006. Chemical changes of kenaf core binderless boards during hot pressing (I): Influence of the pressing temperature condition. Journal of Wood Science 52(3): 244-248.

Panyakaew, S., Fotios, S. 2011. New thermal insulation boards made from coconut husk and bagasse. Energy and Building 43(7): 1732-1739.

Park, B.D., Kang E.C., Lee, S.M., Park, J.Y. 2016a. Formaldehyde emission of wood-based composite panels with different surface lamination maerials using dessicator method. Journal of the Korean Wood Science and Technology 44(4): 600-606.

Park, Y., Park, J.H., Yang, S.Y., Chung, H., Kim, H., Han, Y., Chang, Y.S., Kim, K., Yeo, H. 2016b. Evaluation of physico-mechanical properties and durability of larix kaempferi wood heat-treated by superheated steam. Journal of the Korean Wood Science and Technology 44(5): 776-784.

Santoso, M., Widyorini, R., Prayitno, T.A., Sulistyo, J. 2017. Bonding performance of maltodextrin and citric acid for particleboard made from nipa fronds. Journal of the Korean Wood Science and Technology 45(4): 432-443.

Seo, J.W., Gang, G.W., Jo, G.H., Park, H. 2018. Study on the physical and mechanical properties of particleboard and oriented strandboard manufactured by tulliptree (Liriodendron tulipifera L.). Journal of the Korean Wood Science and Technology 46(1): 67-72.

Shafie, S.M., Mahlia, T.M.I., Masjuki, H.H., AhmadYazid, A. 2012. A review on electricity generation based on biomass residue in Malaysia. Renewable and Sustainable Energy Reviews 16(1): 5879-5889.

Shu, L., Berndt, C.C., Hodzic, A. 2006. Sugar cane bagasse fibre for sustainable manufacturing: an overview of application. Proc. ACUN-5, "Development in Composites; Advanced, Infrastructural, Natural, and Nano-Composites, UNSW, Sydney, Australia, 11-14 July 2006.

Van Hoest, P.J. 2006. Rice straw, the role of silica and treatments to improve quality. Animal Feed Science and Technology 130(3): 137-131.

Vela'squez, J., Ferrando, F., Salvado, J. 2002. Binderless fiberboard from steam exploded miscanthus sinensis: 
Influence of Rice Straw, Bagasse, and their Combination on the Properties of Binderless Particleboard

the effect of a grinding process. European Journal of Wood and Wood Products (Holz als Roh-und Werkstoff) 60(4): 297-302.

Widyorini, R., Higashihara, T., Xu, J., Watanabe, T., Kawai, S. 2005a. Self-bonding characteristics of binderless kenaf core composite. Wood Science and Technology 39(8): 651-662.

Widyorini, R., Xu, J., Umemura, K., Kawai, S. 2005b. Manufacture and properties of binderless particleboard from bagasse I: effects of raw material type, storage methods, and manufacturing process.
Journal of Wood Science 51: 648-654.

Xu, J., Sugawara, R., Widyorini, R., Han, G., Kawai, S. 2004. Manufacture and properties of low-density binderless particleboard from kenaf core. Journal of Wood Science 50(1): 62-67.

Zhang, Y.H., Huang, Y.X., Ma, H.X., Yu, W.J., Qi, Y. 2018. Effect of different pressing process and density on the dimensional stability and mechanical properties of bamboo fibre-based composites. Journal of the Korean Wood Science and Technology 46(4): 355-361. 